\title{
DESAFIO E PERSPECTIVAS NO PROCESSO DE ENSINO DO ESTUDANTE DA EJA
}

Rejane Aparecida de Oliveira

Co autor Walto Luiz da Silva

Aluna Centro Universitário

\section{RESUMO}

Este artigo tem como objetivo abordar e analisar quais são os desafios encontrados no processo de ensino aprendizagem do estudante da EJA, onde o aluno em qualquer modalidade de ensino, nem sempre vai à escola para cumprir com uma obrigação, mas sim para agregar conhecimentos para sua vida profissional e em especial estes estudantes. Por estarem vários anos fora da escola já vêm com um comprometimento maior, porém o desafio quanto à aprendizagem é muito grande. O percurso metodológico constou de uma revisão bibliográfica sobre o tema, a partir de consultas em livros, revistas e artigos científicos, com ênfase na discussão sobre a educação e a responsabilidade da escola no aprendizado dos jovens adultos.

\section{Palavras-Chave: Aprendizagem, Desafios, EJA}




\section{1- INTRODUÇÃO}

Os adultos não se diferenciam do perfil dos jovens no tocante a frequentarem a escola depois de uma longa jornada de trabalho, em busca de um sonho abandonado por motivos que vão desde os pais e esposos que não permitiam que estudassem, pois achavam que não havia necessidade, até as mulheres pela urgência de sustento dos filhos, que em muitos casos ficam grávidas na adolescência e com isso abandonam os estudos, retornando anos mais tarde à escola.

Nenhuma ação educativa pode prescindir de uma reflexão sobre o homem e de uma análise sobre suas condições culturais. Não há educação fora das sociedades humanas e não há homens isolados (...). Se a vocação ontológica do homem é a de ser sujeito e não objeto, só poderá desenvolvê-la na medida em que, refletindo sobre suas condições espaços-temporais, introduzse nelas, de maneira crítica. (FREIRE, 1979)

No pensamento de Freire, é necessário que o homem não somente esteja na realidade, mas esteja com ela, pois assim poderá desenvolver relações contínuas.

Esses estudantes, na sua maioria, carregam marcas profundas de desigualdade social. São homens e mulheres que, com sua experiência histórica, política, cultural e social, retornam à escola para darem continuidade a seus estudos, uma vez interrompidos ou negado pela necessidade de sobrevivência. E o professor, disseminador do conhecimento, poderá auxiliálos utilizando-se de metodologias modernas (FREIRE, 1996), bem como trabalho em grupo, estudos de casos, fazendo com que os mesmos compreendam o que está sendo ensinado com sua experiência de vida.

Essa concepção de educação traz o trabalho para a posição central, analisar o processo histórico da constituição do homem, perceber as relações pertinentes ao trabalho e, dentre elas, a educação formal como uma das possibilidades de preparação para o trabalho no capitalismo.

O capitalismo vive um novo padrão de acumulação decorrente da globalização da economia e da reestruturação produtiva, que passa a determinar um novo projeto educativo para os trabalhadores, independentemente da área, das atribuições ou do nível hierárquico em que atuem, pois vivemos na era da globalização, onde novas exigências de competitividade é um fator marcante.

\section{2- REFERENCIAL TEÓRICO}

\section{2-1 CONCEPÇÃO DE ENSINO E O MUNDO DO TRABALHO}

A EJA tem suas raízes no período colonial onde os religiosos propiciavam uma educação missionária, numa perspectiva de evangelização, conduta comportamental e os ensinamentos necessários para a sustentação da economia colonial (1500 - 1822).

Nos dias atuais o ensino na EJA requer um novo pensar acerca das políticas educacionais e das propostas de (re)inclusão desses discentes nas redes de educação pública no Brasil, onde alfabetizar é somente a primeira parte do processo, pois para uma pessoa adulta retornar seus estudos, o desejo maior é o de se preparar para o trabalho, ter autonomia e de ser um bom 
profissional.

Promover o ensino do trabalhador-estudante na EJA não é tarefa fácil, pois se sabe que eles carregam consigo uma série de experiências, de vivências que não são sistematizadas, mas de um grande valor para enriquecer seu aprendizado. A grande maioria desses alunos retorna à escola novamente porque a necessidade social e a demanda do mercado de trabalho os obrigam a se atualizarem para continuarem exercendo um cargo profissional ou, até mesmo, mudarem de profissão. Enfim, são pessoas que retomam o que lhes foi negado pela necessidade de sobrevivência, cujas contradições, ao longo da história, apontam a educação formal como direito de todos e, ao mesmo tempo, as condições reais muito cedo são para eles obrigação de prover sua subsistência.

A diversidade em sala de aula é um dos desafios enfrentados por esses alunos, pois implica diretamente no ensino-aprendizagem. Uma das queixas são as dificuldades encontradas em algumas disciplinas, que para eles são difíceis. Um exemplo à matemática, que para muitos é um bicho de sete cabeças, mas por esse motivo o professor deve ser dinâmico, desenvolver o conhecimento e a habilidade de cada aluno envolvendo-o em exemplos práticos do seu dia a dia, mostrar que essa e outras disciplinas são importantes para sua formação, favorecendo o diálogo entre sua visão de mundo e do aluno, caracterizando o processo educativo como a reflexão sobre os conhecimentos, que estão em constante transformação, onde tanto o professor quanto o aluno estejam permanentemente em processo de aprendizagem.

È necessário rever os saberes escolares apropriados à vida adulta, as habilidades de leitura, escrita, comunicação, cálculo, os saberes científicos sobre a natureza e a sociedade, mas não tratados de maneira infantilizada. Constantemente tem que ser perguntado que saberes sociais é apropriado, como articulá-los com as experiências dos alunos e como incorporar nos processos de aprendizagem as vivências socioculturais, cognitivas, comunicativas desses jovens e adultos. O que implica o desenvolvimento de práticas pedagógicas que valorizem suas experiências e seus conhecimentos prévios e considerem o vínculo entre educação, trabalho, práticas sociais e culturais. (ARROYO, 2006).

\section{2-2 FORMAÇÃO DO TRABALHADOR}

No período imperial, a primeira Constituição de 1824, assegurou no campo da lei, a formação denominada "primária e gratuita para todos os cidadãos". Sob influência europeia, tornou-se uma constante nas constituições brasileiras, mesmo que somente no campo da lei. A formação do trabalhador neste período contou com as academias militares, entidades filantrópicas e liceus de artes e ofícios. (MAFREDI, 2003)

Na Primeira República, a Constituição de 1891 consagrou a ideia de responsabilizar as Províncias e os Municípios pelo ensino básico. Dessa forma, continuava consolidada a formação para um grupo minoritário, as elites, impedindo uma educação ampla, onde todos teriam direito ao ensino básico, já que as Províncias apresentavam fragilidade econômica, além de ficarem à mercê da política das oligarquias regionais. Nesta Constituição também foi marcada pela exclusão de adultos analfabetos nas eleições e que, nesse período, a grande maioria da população adulta não sabia ler nem escrever, onde muitos não podiam exercer seus direitos.

Na década de 1930, a Educação de Jovens e Adultos aparece de modo explícito na primeira 
Constituição do Governo de Vargas.

O marco na história da EJA no Brasil ocorreu no ano de 1958, com o "Seminário Regional de Recife", evento preparatório para o "II Congresso Nacional da Educação de Adultos". Nele, o educador Paulo Freire chamou a atenção para a necessidade de revisão dos métodos e processos educativos até então adotados, na perspectiva de assegurar uma maior participação do educando no seu processo de aprendizagem. Nesse sentido, propunham-se discussões, trabalhos em grupos e a utilização de recursos audiovisuais, a fim de que fossem suscitadas reflexões sobre a importância da construção de seu próprio conhecimento.

Diante das grandes mudanças geradas no mundo do trabalho pela reestruturação capitalista, o debate em torno da formação do trabalhador ganhou força nos mais diferentes setores da sociedade. As discussões sobre o "novo trabalhador" não se restringiram apenas nos detentores do capital, mas difundiram-se amplamente nos setores mais organizados da sociedade.

Por meio do trabalho, o ser humano constrói sua própria história, reunindo conhecimentos científicos e transformando concretamente o meio ambiente e a sociedade.

O trabalho assim como na sociedade, deve ser transformado, e é no processo dessa transformação onde o indivíduo atual alcançará sua verdadeira dimensão humana. A função pedagógica do trabalho material, como a da sociedade em geral, não depende apenas das condições em que é dado ao homem, mas também, sobretudo da luta dos homens contra essas condições. Uma vez mais, a relação pedagógica homem-ambiente não é unidirecional, mas dialética. (ENGUITA, 1993).

O estudante da EJA, com sua formação interrompida, em geral, insere-se no mercado de trabalho muito cedo, enfrenta situações precárias de condições de trabalho e baixos salários. Atualmente com o avanço tecnológico muitos desses estudantes não têm conhecimento quanto ao uso de computadores e ao chegarem ao ambiente escolar, eles percebem que a didática dos professores e os recursos por eles utilizados mudaram. Deparando-se com novas tecnologias, assustam-se e sentem grandes dificuldades de adaptação.

O mundo vive uma revolução tecnológica que traz como bagagem a transformação do pensamento, da ação e do comportamento. Presencia-se a criação de um novo cenário mundial.

No princípio, alguns alunos da EJA em especial os de mais idade têm resistência ao novo, em especial as aulas de informática, por acreditarem ou pensarem que não lhes seria útil, já que estão "velhos" para aprender manusear o computador e que não seriam capazes de utilizar tal ferramenta. Muitos se sentem inseguros, apresentam dificuldade de coordenação motora ao segurar o mouse, ao teclar, não conseguem ler as letras de fonte pequenas, e ficam envergonhados de solicitar constantemente a atenção do professor. Para muitos é um instrumento novo, que lhes traz medo, e ao mesmo tempo proporciona-lhes satisfação.

Ao contrário desses alunos de mais idade, os mais jovens, mesmo sem nunca terem tido contato anteriormente com o computador, sentem-se mais eufóricos, querem usar a internet.

Com base nas pesquisas realizadas, foi possível evidenciar que os jovens e adultos buscam pela sobrevivência, vivem numa jornada dupla entre o trabalho e a escola, onde o motivo que os levaram a deixar os estudos são os mesmos do retorno, onde pelo sustento da família acabam ingressando ao trabalho muito cedo. Porém, após alguns anos, veem nos estudos um caminho para melhorarem seus salários e sua profissão e que por conta do avanço tecnológico e da economia têm feito com que sintam a necessidade de retornar à sala de aula para aprimorar seus conhecimentos adquiridos ao longo da vida. 


\section{BIBLIOGRAFIA}

ARROYO, Miguel. Dimensões formadoras da vida adulta. Petropolis, RJ: Vozes, 2006.

ENGUITA, Mariano F. Trabalho, escola e ideologia: Marx e a crítica da educação. Porto Alegre: Artes Médicas Sul, 1993.

FREIRE, Paulo. Educação e mudança. Tradução de Moacir Gadotti e Lilian Lopes Martin. Rio de Janeiro: Paz e Terra, 1979.

FREIRE, P. Pedagogia da Autonomia: Saberes necessários à prática educativa, Paulo Freire São Paulo: Paz e Terra, 1996.

GERMANO, José Willington. Estado, militar e educação no Brasil (1964-1985). São Paulo: Cortez, 2005.

HOFFMANN, Jussara. Avaliação mito \& desafio: uma perspectiva construtiva. 29. Ed. Porto Alegre: Mediação, 2000.

MANFREDI, Silvia Maria. Educação profissional no Brasil. São Paulo: Cortez, 2003.

SOARES, Leôncio, José Gomes. Educação de Jovens e Adultos/ Leôncio José Gomes Soares. Rio de Janeiro: DP \& A, 2002. 